Cinémas

Revue d'études cinématographiques

Journal of Film Studies

\title{
Textes d'Eisenstein cités dans l'ensemble du numéro (par ordre chronologique de parution)
}

Volume 11, numéro 2-3, printemps 2001

Eisenstein dans le texte

URI : https://id.erudit.org/iderudit/024856ar

DOI : https://doi.org/10.7202/024856ar

Aller au sommaire du numéro

Éditeur(s)

Cinémas

ISSN

1181-6945 (imprimé)

1705-6500 (numérique)

Découvrir la revue

Citer cet article

(2001). Textes d'Eisenstein cités dans l'ensemble du numéro (par ordre

chronologique de parution). Cinémas, 11(2-3), 271-272.

https://doi.org/10.7202/024856ar d'utilisation que vous pouvez consulter en ligne. 


\section{Textes d'Eisenstein cités dans l'ensemble du numéro (par ordre chronologique de parution)}

1942, The Film Sense. Jay Leyda (ed.). New-York: Harcourt/ Brace; London: Faber \& Faber, 1943.

1949, Film Form: Essays in Film Theory. Jay Leyda (ed.), New York: Harcourt/Brace; London: Dobson, 1951.

1964-1971, Izbranniié proizvédéniia v 6 tomakh [œuvres choisies en six volumes]. Moscou: Iskousstvo.

1958, Réflexions d'un cinéaste. Moscou: Progrès.

1969, "Hors Cadre» [1929] dans Cahiers du cinéma, n 215, octobre.

1970, "Le retour du soldat du front ", Cahiers du cinéma, $\mathrm{n}^{\circ} 225$, nov.-déc.

1973, [Eisenstein/Nijny]. Mettre en scène. Paris: UGE 10/18Cahiers du cinéma.

1974, Au-delà des étoiles (CEuvres, Tome 1). Paris: UGE 10/18Cahiers du cinéma.

1976a, Le Film: sa formelson sens. Paris: Christian Bourgois.

1976b, La Non Indifférente Nature 1 (Euvres, Tome 2). Paris: UGE $10 / 18$.

1978a, Mémoires 1 (Euvres, Tome 5). Paris: UGE 10/18Éditions Sociales.

1978b, La Non Indifférente Nature 2 (Euvres, Tome 4). Paris: UGE 10/18.

1980a, Cinématisme. Peinture et cinéma (dir: François Albera). Bruxelles: Éditions Complexe.

1980b, Mémoires 2 (Euvres, Tome 5). Paris: UGE 10/18.

1982, Il Colore (vol. III, tomo II). Venezia : Marsilio.

1984, On the Composition of the Short Fiction Scenario. Calcutta: Seagull Books and Eisenstein Cine Club.

1985a, Eisenstein 2. A Premature Celebration of Eisenstein's 
Centenary. Calcutta: Seagull Books.

$1985 \mathrm{~b}$, Teoria generale del montaggio (vol. IV, tomo I). Venezia: Marsilio.

1985c, Mémoires 3 (Euvres, Tome 6). Paris: UGE 10/18.

1986a, Le Mouvement de l'art. Paris : Cerf.

1986b, Eisenstein On Disney. Calcutta: Seagull Books.

1986c, Il montaggio (vol. IV, tomo II). Venezia : Marsilio.

1987, The Psychology of Composition. Calcutta : Seagull Books.

1988, Writings 1922-1934 (Selected Works, vol. I). London: BFI Publishing/Bloomington: Indiana University Press.

1989a, La Regia (vol. V, tomo I). Venezia : Marsilio.

1989b, "Gogol' i kinojazyk " dans Kinovedtcheskie zapiski, n 4.

1991a, Toward a Theory of Montage (1937-40) (Selected Works, Vol. II). London: BFI Publishing.

1991b, Walt Disney. Strasbourg: Circé.

1993a, Stili di regia (vol. V, tomo II). Venezia: Marsilio.

1993b, [Eisenstein, Alexandrov], "Le Bazar de la concupiscence» dans Novoe literaturnoe obozrenie, $\mathrm{n}^{\circ} 4$.

1995, Beyond the Stars: The Memoirs of Sergei Eisenstein (Selected Works, Vol. IV). Calcutta: Seagull Books. London: BFI.

1996, Writings 1935-47 (Selected Works, Vol. III). London: BFI Publishing.

1997, Memouary 1 et 2. Moscou: Troud-Musée du cinéma.

1997/1998, "Lettres à Péra Attachéva» dans Kinovedtcheskie zapiski, nos $36 / 37$.

1998, Il movimento espressivo. Scritti sul teatro. Venezia: Marsilio.

1999a, M L B. Plongée dans le sein maternel. Paris: Hoëbeke.

1999b, "[Final Mednogo vsadnika]. Fragmenty iz knigi Montaz ", Kinovedtcheskie zapiski, $\mathrm{n}^{\circ} 42$. 